\title{
HISTÓRIA INDÍGENA NO PERÍODO REPUBLICANO E OS LIVROS DIDÁTICOS DE HISTÓRIA: UMA REFLEXÃO NECESSÁRIA
}

\author{
INDIGENOUS HISTORY IN THE BRAZILIAN REPUBLICAN PERIOD AND THE \\ HISTORY TEXTBOOK: A NECESSARY REFLECTION
}

André Luis Bertelli Duarte ${ }^{1}$ Felipe Cesar Peres Tedeschi

\begin{abstract}
RESUMO: O ensino da história e cultura dos povos indígenas no Brasil vivenciou avanços significativos nos últimos anos impulsionados, sobretudo, pela sua obrigatoriedade definida pela lei $11.645 / 08$. É inegável que esforços têm sido direcionados por professores e demais envolvidos na educação básica no sentido de oferecer um ensino de qualidade que seja capaz de responder ao desafio da educação para o exercício da diversidade em sua relação com os povos indígenas. Alguns desafios, entretanto, ainda se projetam no horizonte destes profissionais. Neste artigo discutimos especificamente a importância da superação de uma "lacuna" existente nos materiais didáticos de história destinados, atualmente, ao público do ensino fundamental, a saber, a pouca ênfase dada aos processos históricos engendrados no período republicano brasileiro que envolvem as diversas etnias indígenas. Sem o enfrentamento destas questões, o ensino da história e cultura destes povos em nossas escolas não conseguirá dimensionar e problematizar as suas diversas demandas históricas e contemporâneas.
\end{abstract}

Palavras-chave: Povos indígenas brasileiros. República. Livros didáticos. História.

ABSTRACT: The teaching of history and culture of indigenous peoples in Brazil has experienced significant advances in recent years driven mainly by its obligation defined by law 11,645 / 08 . It is undeniable that efforts have been directed by teachers and others involved in basic education, in order to provide quality education that is able to meet the challenge of education for the exercise of diversity in its relationship with indigenous peoples. Some challenges, however, still jut on the horizon of these professionals. In this article specifically we discussed the importance of overcoming a "gap" in existing teaching materials of history to the public elementary school today, namely the little attention given to historical processes engendered in the Brazilian republican period involving the various indigenous ethnic groups. Without addressing these issues, the history of education and the culture of these people in our schools can not scale and discuss their different historical and contemporary demands.

Keywords: Indigenous peoples in Brazil. Republic. Textbooks. History.

\footnotetext{
${ }^{1}$ Professor do EBTT da Universidade Federal de Uberlândia. Doutor em História pela Universidade Federal de Uberlândia.

2 Graduando em História pela Universidade Federal de Uberlândia.
} 


\section{Introdução}

A lei 11.645, promulgada em março de 2008, representou um grande avanço para os diversos movimentos sociais brasileiros que viam a obrigatoriedade do ensino da temática indígena nas escolas como um passo fundamental na reafirmação de identidades, na desconstrução de estereótipos e preconceitos e na valorização de um protagonismo histórico. O ensino da temática indígena dentro das escolas, é de extrema importância para repensarmos uma diversidade de problemas presentes atualmente em nosso país, sobretudo, aqueles ligados às formas de convívio com as diferenças.

Apesar da promulgação da lei ter significado um grande avanço, acreditamos que ainda temos muitos desafios a serem superados, problemas que precisam ser analisados e resolvidos, tais como a formação inicial e continuada de profissionais sobre a temática; a escassez de pesquisas que, normalmente, circulam em um domínio restrito; a falta de interação entre as diversas instituições que tratam dos interesses dos povos indígenas e a escola, entre outros. O problema do qual nos ocuparemos neste artigo, entretanto, se relaciona com as abordagens construídas sobre os povos indígenas nos livros didáticos de história no ensino fundamental, especificamente, sobre a importância do trabalho com a história indígena do período republicano brasileiro para a compreensão das questões contemporâneas vivenciadas por estas populações.

No desenvolvimento de um projeto de pesquisa vinculado à pró-reitoria de graduação da Universidade Federal de Uberlândia (PROGRAD/UFU), pesquisamos a abordagem de questões relacionadas aos povos indígenas no contexto conhecido como período republicano brasileiro presentes nos livros didáticos de história do ensino fundamental. As primeiras etapas do projeto envolveram a seleção e análise de coleções de livros didáticos que compõem o acervo do laboratório de história da Escola de Educação Básica (ESEBA/UFU), do 60 ao 90 ano do ensino fundamental, publicadas nos anos que se seguiram à promulgação da lei $11.645 / 08^{3}$.

\footnotetext{
${ }^{3}$ No desenvolvimento do projeto, analisamos as seguintes coleções didáticas de História do ensino fundamental II: (BRAICK, 2011; CAMPOS; CLARO; DOLHNIKOFF, 2012; DOMINGUES, 2009; BOULOS JUNIOR, 2012; MARINO; STAMPACCHIO, 2012; PANAZZO; VAZ, 2012).
} 
Na análise destas coleções, procuramos evidenciar, qualitativamente, como os povos indígenas são retratados, se elas contribuem efetivamente para desconstruir estereótipos e preconceitos sobre esses grupos, em quais processos históricos estes povos aparecem, como as suas lutas e estratégias historicamente engendradas no convívio com a sociedade nacional são retratadas, e, quantitativamente, quantas páginas e capítulos são reservados à temática indígena, assim como o número de imagens, textos, bibliografias, sugestões de leituras e acesso a outras fontes de informação.

O objetivo principal do nosso estudo foi analisar o atual estágio das abordagens dos livros didáticos de história do ensino fundamental referentes à temática da história e cultura dos povos indígenas brasileiros e, a partir disso, propor caminhos e desafios que devem ser enfrentados pelos autores e professores, a fim de dar-lhes subsídios que garantam o entendimento das diversas experiências e perspectivas envolvidas na história destes povos e culturas.

\section{Os Povos Indígenas e o livro didático}

Já é consenso na historiografia da educação brasileira que o livro didático não pode ser o único recurso disponível ao professor, e que também não deveria ser a única fonte de leitura disponibilizada aos alunos, mas temos que admitir que muitas vezes ele acaba sendo o único material disponível, o que atesta sua importância no processo de ensino e aprendizagem dos estudantes da educação básica em nosso país. O livro didático muitas vezes acaba sendo visto como uma fonte de conhecimento acabada, não passível de críticas, o que torna ainda mais urgente a reflexão sobre o seu papel, seus interesses, perspectivas, ditos e nãoditos (BITTENCOURT, 1997).

A análise das coleções didáticas do componente curricular História para os anos finais do Ensino Fundamental constituintes dos últimos PNLDs revelou que a maioria dos autores ainda foca suas lentes, prioritariamente, sobre os povos indígenas brasileiros em dois momentos históricos específicos: primeiro, no período colonial; segundo, no período da redemocratização após o fim da 
ditadura militar, mais especificamente no contexto da promulgação do texto constitucional de 1988 e nos dias atuais.

Das seis coleções que analisamos, cinco organizam os temas de maneira linear, a partir da divisão tradicional da história em períodos (história Antiga, Medieval, Moderna e Contemporânea) definidos por uma matriz eurocêntrica. A história do Brasil é pensada, nesta lógica, a partir dos marcos tradicionais da história política (Brasil Colônia, Império e República). Apenas uma coleção, organiza os temas por eixos temáticos (História - coleção link) dos autores Marino e Stampacchio (2012). Esta constatação é importante na medida em que esta estrutura dominante nos livros didáticos contribui para a reafirmação de um currículo eurocêntrico no qual a história dos povos indígenas aparece integrada à lógica da história europeia e capitalista.

Entendemos, de imediato, que esta abordagem presente nos livros didáticos cria uma ponte entre os indígenas sujeitos da chegada dos europeus à América e o período colonial e a atualidade, ou seja, os indígenas geralmente aparecem apenas nos primeiros contatos com o "homem branco" e, mais adiante, na atualidade relacionados com algumas demandas contemporâneas, como a demarcação de terras, por exemplo.

Esta forma de abordar, genericamente, a história dos indígenas no Brasil está presente em praticamente todas as coleções analisadas. Em Jornadas.hist, da editora Saraiva, no livro do 70 ano, há um capítulo destinado exclusivamente aos povos americanos, uma espécie de pré-história da América anterior à chegada dos europeus. Neste capítulo, as autoras apresentam a diversidade cultural dos povos que habitavam o território anteriormente à chegada dos portugueses, abordam o tema do contato entre europeus e índios numa perspectiva de valorização da multiplicidade de interpretações históricas e apresentam, numa sessão especial intitulada "Em ação", um trabalho de pesquisa sobre os direitos indígenas no Brasil contemporâneo a partir da luta dos indígenas pela demarcação de suas terras cuja posse foi garantida pela Constituição Federal de 1988 (PANAZZO, VAZ, 2012).

Uma abordagem mais detalhada somente desses dois contextos históricos contribui para a reprodução de certas ideias preconceituosas existentes ainda hoje sobre esses povos, como a noção de que "ficaram no passado", que têm 
tradições estáticas, que não são sujeitos históricos, e que foram e são totalmente passivos frente à tradição europeia, ou seja, num primeiro momento teriam sido meras vítimas de um processo de expansão comercial, para depois de quase 500 anos emergirem novamente como sujeitos que conquistam direitos constitucionais importantes para a sua sobrevivência. Quando o livro didático traz a questão da demarcação de terras, sem apresentar elementos históricos envolvidos neste processo, tem-se a impressão que o Estado concedeu/concede essas terras aos indígenas de bom grado, e não que a demarcação de terras é fruto de intensas lutas de diversos movimentos sociais, com destaque para o protagonismo dos próprios povos indígenas, frente aos processos de expropriação de suas terras.

Esta constatação inicial traz vários outros desdobramentos que apresentaremos mais adiante; ela não impede, entretanto, que possamos visualizar e explicitar, por meio dos resultados obtidos nas análises das coleções, os avanços que os livros didáticos apresentaram nos últimos anos a respeito do tratamento da temática indígena, apontando os avanços obtidos pelos livros didáticos e alguns desafios que ainda se encontram no horizonte destas produções.

No livro A temática Indígena na escola: novos subsídios para professores de $1^{0}$ e $2^{0}$ graus, organizado por Aracy Lopes da Silva e Luís Donizete Benzi Grupioni, publicado em 1995 e que desde então se tornou uma importante referência para os interessados no tema, encontramos um texto do próprio Luís Donizete Grupioni no qual estão sistematizados os principais problemas e desafios relacionados à abordagem da temática indígena postos pelos livros didáticos na época. Este texto é importante para analisarmos os avanços obtidos desde então, pois permite a realização de um exercício crítico comparativo que nos possibilita a verificação dos problemas que foram superados pelos autores dos livros didáticos e quais os passos que ainda precisam ser percorridos.

O primeiro desafio levantado por ele à época dizia respeito a constatação de que os livros não tratavam da origem dos povos do continente americano e não abordavam suas histórias anteriores à chegada dos colonizadores, reforçando, portanto, uma perspectiva eurocêntrica da história do continente americano (GRUPIONI; SILVA, 1995, p. 487). Nos livros didáticos que analisamos, 
constatamos a preocupação dos autores em apresentar o povoamento do continente americano sob diferentes olhares, mostrando tanto a teoria do estreito de Bering como a teoria Malaio-Polinésia, em trabalhar com dados dos diversos sítios arqueológicos como fontes de informações e de novas teorias, em explicar os diferentes modos de vida dos diversos habitantes do continente ao longo do tempo, entre outras. Esta perspectiva reforça o argumento de que os povos indígenas brasileiros são parte de um processo de ocupação do continente anterior à chegada dos colonizadores europeus e que seriam, portanto, os primeiros habitantes do Brasil.

Outras críticas que o autor sinalizava em seu artigo diziam respeito à abordagem simplista que os livros didáticos traziam em relação à sociedade, às formas de organização, à cultura e religião dos povos indígenas, caracterizandoos como viventes de sociedades sem escrita, sem governo e sem tecnologia. Também criticava a maneira como os livros didáticos abordavam os documentos produzidos na época da colonização, tais como os escritos dos jesuítas, cronistas e viajantes, de forma descontextualizada e isolada, numa perspectiva que reforçava os estereótipos apresentados anteriormente.

Ao analisarmos a coleção História em documento de Joelza Ester Domingues (2009), notamos um avanço em relação a essas questões, já que a autora apresenta diversos documentos da época colonial e, além de contextualizá-los, nos mostra diferentes pontos de vista sobre o mesmo evento, indicando que todo documento produzido está inserido em um contexto histórico e que não é neutro, reforçando a noção de que não existem visões verdadeiras eu falsas sobre os eventos e sim diferentes versões dotadas de interesses que são históricos.

Em seu texto-síntese Grupioni também chamava a atenção para o problema que os livros didáticos apresentavam com relação a informações redundantes e genéricas sobre os povos indígenas, como a de que eles andavam nus, fabricavam canoas, comiam mandiocas e gostavam de se enfeitar. Segundo ele, essas informações eram simplistas e não davam conta da complexidade desses povos e de suas culturas, já que deixava de considerar, por exemplo, os rituais, os costumes, a simbologia material e imaterial, entre outros aspectos. Nesse sentido, os livros didáticos analisados, objetos deste artigo, apresentam informações mais complexas, como por exemplo, a coleção estudar história, de 
Patrícia Ramos Braick (2011), que explica os aspectos simbólicos e mostra a importância da guerra e dos rituais antropofágicos para os Tupis:

\begin{abstract}
A guerra era um costume central da cultura Tupi. Guerrear era uma prática ritual, vista como um meio de vingar os parentes mortos e de afirmar a força e a liderança da tribo. Depois da guerra e da captura do inimigo vinha a antropofagia, um ritual de sacrifício humano que deixou os europeus perplexos.

$\mathrm{Na}$ cultura guerreira dos Tupi, derrotar o inimigo na guerra e devorá-lo em um ritual antropofágico significavam a ocasião de maior triunfo [...] para o prisioneiro, morrer em combate era um meio de unir-se aos ancestrais; para os vencedores, comer a carne do inimigo era uma maneira de assimilar sua força e coragem e vingar a morte de parentes (BRAICK, 2011, p. 202).
\end{abstract}

A autora também descreve, neste trecho, os aspectos materiais e ritualísticos da antropofagia e apresenta uma ilustração de Duas viagens ao Brasil, de Hans Staden. No final da página também há a indicação do filme Hans Staden, de Luiz Alberto Pereira, com a sua sinopse. Essas informações auxiliam a desmistificar alguns preconceitos acerca dos rituais antropofágicos praticados por determinadas etnias no passado.

Gruppioni ainda apontava, em seu texto, para a caracterização dicotômica que os livros didáticos faziam dos indígenas como bons/maus selvagens, construindo uma visão romantizada - em que eles apareciam em contato com a natureza, eram inocentes, ingênuos, puros, não tinham maldades - ou traziam a visão do indígena bárbaro, sem governo, sem religião, que não queria trabalhar e que necessitava ser civilizado. Essas duas visões opostas trafegaram por muito tempo tanto na historiografia como na literatura. Pelo que pudemos ver nos livros didáticos analisados, essas duas visões dicotômicas do indígena já foram superadas, e foram substituídas por uma tentativa de percebê-los como sujeitos históricos que se apropriam dos processos históricos em que estão envolvidos e que criam diferentes estratégias para lidar com eles. No livro do $8^{\circ}$ ano da coleção História, da IBEP, os autores tratam das primeiras formas de exploração do território brasileiro e da força de trabalho dos indígenas do litoral pelos portugueses (o escambo) da seguinte maneira:

Ao impor seus valores, os conquistadores europeus desorganizaram as culturas dos povos que ali habitavam. Alteraram o ritmo de vida desses povos, pois mudaram a relação que mantinham entre si e com a terra, o trabalho, os animais e as forças da natureza [...] Não foram poucos os indígenas que desapareceram da região litorânea. Muitos migraram par o 
interior, entrando em choque com outros povos, o que só fez crescer ainda mais o extermínio da população nativa (MARINO, STAMPACCHIO, 2012, p.149).

Ressalta-se, no trecho citado, o protagonismo indígena diante da situação de desestabilização causada pela exploração do pau-Brasil, que responde à situação através da migração massiva para o interior. Os autores poderiam ir ainda mais além demonstrando a interpretação dos próprios indígenas sobre a troca de mercadorias, a partir dos referenciais da economia dos povos tupi do litoral, no entanto, é perceptível que as dicotomias provenientes do romantismo foram superadas. Outro autor aborda o mesmo processo de migração nos primeiros anos da colonização portuguesa sob o prisma cultural da busca da "terra sem males", componente da mitologia tupi (BOULOS JUNIOR, 2012).

Outros avanços que gostaríamos de chamar atenção dizem respeito à desconstrução de estereótipos: grande parte dos livros analisados auxilia na desmistificação da ideia engendrada no imaginário popular sobre a identidade indígena, caracterizada pelos clichês da nudez, do isolamento na floresta, das pinturas corporais e da inacessibilidade à tecnologia. Quando o livro didático elabora uma abordagem que evidencia as tradições como construções, e portanto, mutáveis, veicula e contextualiza imagens com indígenas vestidos, apropriando-se de diferentes tecnologias, participando de processos educativos, ele contribui para desconstruir preconceitos e estereótipos. A maioria das coleções já fala sobre os quatros principais troncos e famílias linguísticas (Tupi, Macro-Jê, Arúak e Karib), e também sobre a grande diversidade de povos existentes no que é hoje o território brasileiro, mostrando através de mapas as localizações das diversas etnias indígenas.

No decorrer da análise das coleções didáticas selecionadas pudemos perceber que nos últimos anos grandes avanços foram incorporados na abordagem da temática indígena, avanços importantes para uma formação adequada e que dê conta de situar a diversidade histórica e contemporânea que caracteriza as culturas indígenas do Brasil. No entanto, ainda temos algumas lacunas que necessitam ser superadas. Esse enfrentamento se faz necessário tanto para uma compreensão efetiva destes povos como protagonistas de suas próprias histórias numa perspectiva que contribua efetivamente para o 
entendimento dos desafios atuais enfrentados por diversas etnias habitantes do Brasil.

Um dos principais problemas que identificamos em todas as coleções didáticas analisadas refere-se à fragmentação da história indígena, que é restrita a capítulos específicos e, não raro, "sessões" à parte no interior de outros capítulos. Este processo já havia sido identificado por Grupioni em 1995, que então chamava a atenção para as consequências do "obscurecimento" da história indígena:

\begin{abstract}
Assim como também são fragmentados os momentos históricos nos quais os índios aparecem. Os livros didáticos produzem a mágica de fazer aparecer e desaparecer os índios na história do Brasil. O que parece mais grave neste procedimento é que, ao jogar os índios no passado, os livros didáticos não preparam os alunos para entenderem a presença dos índios no presente e no futuro. E isto acontece, muito embora, as crianças sejam cotidianamente bombardeadas pelos meios de comunicação com informações sobre os índios hoje. Deste modo, elas não são preparadas para enfrentar uma sociedade pluriétnica, onde os índios, parte de nosso presente e também de nosso futuro, enfrentam problemas que são vivenciados por outras parcelas da sociedade brasileira (GRUPIONI; SILVA, 1995, p. 489).
\end{abstract}

A perpetuação desta "mágica de fazer aparecer e desaparecer os índios na história do Brasil", que se efetiva não apenas nos livros didáticos, mas também na própria concepção curricular do ensino de história, concorre para criar um ensino da história indígena fragmentado, desconectado com o presente, incapaz de formar entendimentos que levem os estudantes a compreenderem efetivamente quem são os povos indígenas brasileiros em sua diversidade histórica e contemporânea. O discente que estuda longamente os temas relacionados ao índio colonial no 70 ano é, adiante, confrontado com os "mesmos índios" reivindicando direitos, terras e soluções governamentais, o que pode levá-lo a pensar sobre algumas questões: "por que eles estão lutando por isso?"; "quem são os seus interlocutores?"; "quem são os seus inimigos: os portugueses, os padres jesuítas ou os bandeirantes?" É em função deste desequilíbrio e dos desdobramentos deste jogo que "revela e esconde", que acreditamos que o principal desafio colocado atualmente, não apenas para os autores de livros didáticos mas para os professores de história de modo geral, é 
lidar com as questões históricas relativas aos povos indígenas que emergem especificamente no período republicano brasileiro.

\section{O desafio da história indígena no período republicano}

A análise de algumas coleções didáticas de História destinadas ao público do Ensino Fundamental revelou que praticamente nenhuma atenção é dada aos processos históricos vivenciados pelos povos indígenas no período republicano brasileiro. Ou quando surgem referências específicas sobre processos históricos que envolvem estes sujeitos neste período específico, elas são genéricas e insuficientes. Em História e Documento do 90 ano, por exemplo, há uma referência ao processo de construção da Transamazônica e à ocupação da Amazônia durante o governo militar e uma referência de que "a imprensa nada divulgou sobre o desmatamento, a invasão de terras indígenas e a apropriação de enormes extensões de terras por poderosos grupos industriais do Sudeste" (DOMINGUES, 2009, p. 226). De quais indígenas a autora está falando? Dos Krenakarore, que foram praticamente dizimados pelo avanço da Transamazônica? As poucas referências que surgem sobre as histórias indígenas no Brasil republicano, via de regra, os designam genericamente como "índios", o que dificulta a compreensão da multiplicidade de sujeitos e processos históricos característicos destes povos.

O "sequestro" da história indígena da maior parte deste período, em nosso entendimento, contribui para a perpetuação de equívocos e preconceitos sobre o lugar da história indígena na história brasileira, principalmente no que se refere ao protagonismo destes povos enquanto sujeitos de processos, transformações e conquistas e, consequentemente, contribui para o obscurecimento da compreensão de questões contemporâneas enfrentadas por muitas destas populações.

Nosso foco sobre o período republicano se deu em função da especificidade do mesmo, pois foi neste momento da história brasileira que uma política indigenista desenvolvida pelo estado avançou de modo consistente, o que não significa dizer que os direitos destes povos foram preconizados e respeitados, 
pelo contrário, o fortalecimento das instituições republicanas permitiu que os próprios indígenas, paulatinamente, se organizassem e passassem a lutar, com o apoio de entidades não-indígenas, pela consolidação de um aparato legal que Ihes garantissem os seus direitos fundamentais num contexto onde, de várias maneiras, o próprio estado atuou no sentido de cerceamento destes direitos.

Neste sentido, o estado brasileiro criou, em 1910, o Serviço de Proteção ao Índio (SPI) que, no início, ficou a cargo do marechal Cândido Rondon, que havia travado contato com várias etnias no centro-norte do território em sua atuação na comissão de linhas telegráficas, que visava integrar todo o território nacional. O SPI surgiu com o objetivo de prestar assistência a todos os índios brasileiros, fornecendo-Ihes educação formal, acesso às inovações tecnológicas e difusão de técnicas agrícolas e ensino da pecuária. Na prática, a atuação do SPI, ao colocarse como aparato do Estado para intermediar os contatos interetnicos gerados pela expansão das fronteiras nacionais, tinha como objetivo integrar os diversos povos indígenas à "comunhão nacional", tornando-os cidadãos brasileiros responsáveis pela proteção das fronteiras do país. Além disso, o órgão também buscava transformar os indígenas em trabalhadores "úteis" ao estado, seja por meio da agricultura, ou ainda em outros serviços como na conservação e reparo das linhas de transmissão telegráficas (FREIRE; OLIVEIRA, 2006).

No momento de criação e início das atividades do SPI, foi produzido e aprovado o primeiro Código Civil brasileiro, de 1916, cujo texto tratava os povos indígenas habitantes do território como "relativamente incapazes" para o exercício de determinados atos da vida civil, por isso, competia ao Estado criar mecanismos de tutela destes povos, aos quais os índios ficariam sujeitos. Por trás destas definições havia um projeto de construção de uma identidade nacional à qual os povos indígenas deveriam pertencer através de um processo de transformação dos seus modos de vida, ou seja, acreditava-se que os indígenas viviam em uma fase anterior do desenvolvimento - ou da "evolução" da cultura humana e que cabia ao Estado promover este desenvolvimento através da educação formal para que os indígenas pudessem participar da "comunhão nacional".

A criação do SPI, somada às definições do código civil de 1916 - que seria, em seus termos gerais, reforçado nas legislações subsequentes -, deu origem a 
uma relação entre os povos indígenas e o Estado brasileiro caracterizada pela perspectiva da tutela. Esse modelo concorre por criar, segundo João Pacheco de Oliveira, um paradoxo cujo entendimento é fundamental para dimensionar as questões da história indígena neste período:

\begin{abstract}
O tutor existe para proteger o indígena da sociedade envolvente ou para defender os interesses mais amplos da sociedade junto aos indígenas? É da própria natureza da tutela sua ambiguidade, as ações que engendra não podendo ser lidas apenas numa dimensão humanitária (apontando para obrigações éticas ou legais), nem como instrumento simples de dominação. É no entrecruzamento destas causas e motivações que deve ser buscada a chave para a compreensão do indigenismo brasileiro, um regime tutelar estabelecido para as populações autóctones que foi hegemônico de 1910 até a Constituição de 1988, perdurando em certa medida até os dias atuais em decorrência da força de inércia dos aparelhos de poder e de estruturas governativas (FREIRE; OLIVEIRA, 2006, p. 115).
\end{abstract}

Em 1967 o SPI foi extinto e foi criada em seu lugar a Fundação Nacional do Índio (FUNAI), que desde então atua como órgão governamental na mediação entre os índios e os não-índios. A FUNAI tinha os seus princípios de ação baseados no mesmo paradoxo fundador do SPI: o "respeito à pessoa do índio e às instituições e comunidades tribais" associado à "aculturação espontânea do índio" e à promoção da "educação de base apropriada do índio visando sua progressiva integração na sociedade nacional". Na prática, a atuação da FUNAI muitas vezes provocou a desestruturação tradicional de sociedades indígenas, bem como a miséria e a propagação de doenças decorrentes do contato (FREIRE; OLIVEIRA, 2006, p. 131).

De fato, todos os textos constitucionais republicanos ou estatutos e leis específicos até a promulgação da Constituição de 1988, atuaram na perspectiva da integração dos indígenas à sociedade nacional por meio da cultura, da educação e do trabalho; não havia a clareza que o território brasileiro era formado por culturas diversas, ou melhor, não havia o interesse político e econômico de reconhecer o multiculturalismo histórico e contemporâneo do Brasil.

O modelo tutelar foi hegemônico até a Constituição de 1988, cuja promulgação do texto, pela primeira vez na história, trata a questão das populações indígenas pela perspectiva do multiculturalismo e não mais na 
perspectiva do integracionismo; em outras palavras, a Constituição cidadã garantiu aos indígenas o direito originário às terras que tradicionalmente ocupam, bem como o usufruto dos recursos naturais e minerais presentes nestas terras. Além disso, reconheceu, pela primeira vez, o direito à diferença cultural, religiosa, linguística etc. a partir do entendimento de que o Brasil é um país composto por muitas culturas. Neste sentido, não havia mais a obrigatoriedade de "integrar" as populações indígenas à "comunhão nacional", preocupação presente nos textos constitucionais anteriores e no Estatuto do Índio de 1973, e, consequentemente, a necessidade da manutenção do regime tutelar. Esta foi, sem sombra de dúvidas, uma conquista que só foi possível pelas ações e estratégias engendradas pelos próprios indígenas em parceira com grupos e instituições não-indigenistas.

A conquista do direito à diferença e a ampliação das tomadas de decisões pelas próprias populações indígenas a partir de 1988 não interrompeu, entretanto, os conflitos nos quais estas populações se viam historicamente inseridas e muito menos apagou as marcas deixadas pelo passado sob a tutela do estado, marcas estas fundamentais para a compreensão do estágio atual da questão indígena e de suas perspectivas futuras.

Muitas destas marcas voltaram ao centro do debate no ano de 2014 na ocasião da divulgação do relatório final da Comissão Nacional da Verdade que, no título II, texto 5, tratou das violações dos direitos humanos dos povos indígenas no período entre os anos de 1946 e 1988. Elaborado sob responsabilidade da pesquisadora Maria Rita Kehl, o referido texto traz a tona episódios de violação dos direitos humanos de várias populações e indivíduos indígenas protagonizados pelo Estado brasileiro, que levaram à conclusão de que mais de 8 mil indígenas foram mortos em função da ação ou omissão do Estado, número que certamente é maior uma vez que a comissão estimou apenas os casos objetos de estudo. ${ }^{4}$

Estes episódios descortinados pelo trabalho da Comissão Nacional da Verdade (CNV) envolvem desde a criação de prisões indígenas durante o regime militar até os diversos processos de atração e contato de povos isolados

\footnotetext{
${ }^{4}$ Sobre este aspecto, o texto da CNV aponta que "o número real de indígenas mortos no período deve ser exponencialmente maior, uma vez que apenas uma parcela muito restrita dos povos indígenas afetados foi analisada e que há casos em que a quantidade de mortos é alta o bastante para desencorajar estimativas". (KEHL, 2014, p. 199).
} 
subsidiados pelo Estado, que levaram à desarticulação de etnias e à morte de vários indivíduos. A maior parte dos episódios, no entanto, refere-se às ações de esbulho dos territórios indígenas promovidas por interesses ligados ao grande capital fundiário em associação com órgãos governamentais estaduais e federais.

\section{0 "caso" das terras indígenas}

Em todas as coleções didáticas de História analisadas em nossa investigação a questão dos territórios indígenas recebe uma atenção especial. Os autores, neste sentido, buscam colocar em relevo as conquistas advindas da Constituição de 1988 que, além de garantir o direito de ocupação dos territórios ocupados tradicionalmente, inovou ao garantir aos indígenas a gestão e usufruto dos recursos naturais existentes nelas. Apesar de eventualmente fazer referências aos conflitos que ainda existem sobre as demarcações (ou a falta delas) das terras indígenas, os autores optam geralmente por apresentar o significado da terra para estas populações nativas e as suas lutas para garantir este direito constitucional - abordagens legítimas e importantes para o tratamento do tema nesta faixa etária específica.

Ao não enfatizar a história republicana anterior ao período da redemocratização, entretanto, estes autores concorrem por esvaziar a perspectiva histórica da questão dos territórios indígenas no Brasil, sobretudo, os embates e interesses envolvidos que são históricos exatamente porque seus "ecos" ainda se fazem sentir no tempo presente. A análise das coleções didáticas em seu conjunto ( $6^{\circ}$ ao $9^{\circ}$ ano) indica que as invasões dos territórios indígenas, as estratégias e os embates enfrentados por estas populações estão fortemente presentes no estudo do período colonial, sobretudo no contexto da expansão do bandeirantismo, mas desaparecem por um grande intervalo temporal, voltando à tona muitos séculos depois, num contexto contemporâneo.

Um olhar mais atento sobre a questão revela não obstante que os processos de invasão e defesa dos territórios indígenas se tornaram muito mais complexos no período republicano, quando o estado brasileiro desenvolveu políticas 
sistemáticas de esbulho de territórios nativos em toda a extensão territorial associado aos interesses de exploração agrária nacionais e estrangeiros.

A laicização do estado brasileiro ocorrida com o advento da República significou o fim da gestão dos territórios indígenas realizada pelos missionários católicos que, no período imperial, retomaram a prática dos aldeamentos em várias regiões. O fim dos aldeamentos missionários desencadeou, em muitos lugares, um processo de abandono das terras designadas para a moradia dos índios, tornando-as terras devolutas. No início da República, as decisões sobre essas terras, de acordo com a $1^{\text {a }}$ Constituição republicana - que não se debruçou de nenhum modo sobre a questão indígena - ficaram a cargo dos governos estaduais. Esta definição dificultou bastante o processo de demarcação de territórios indígenas desencadeado pelos agentes do SPI que, em muitos casos, tiveram suas propostas negadas pelos governos estaduais. Como estes governos estaduais estavam fortemente subordinados às oligarquias agrárias regionais não é de se espantar que muitos territórios tradicionalmente ocupados por índios foram considerados devolutos e apropriados por fazendeiros e posseiros.

A Constituição de 1934 foi a primeira constituição republicana no Brasil que tratou especificamente da questão dos territórios indígenas. Segundo o texto, que tratava as populações nativas na perspectiva do integracionismo, seria respeitada a posse das terras às populações indígenas que se encontrassem permanentemente ocupadas, sendo vedado aliená-las. O texto também transferia a competência de decisão sobre as terras indígenas para o governo federal, o que não pôs fim ao conflito de competências que, de acordo com João Pacheco de Oliveira e Carlos Rocha Freire, só foi resolvido com a promulgação do Estatuto do Índio em 1971: "de um lado, a União, durante décadas, não regulamentou $\mathrm{o}$ artigo constitucional sobre as terras indígenas, reeditado em 1937 e 1946 apenas com pequenas alterações; de outro, os estados aproveitaram a situação para considerar as terras indígenas como devolutas e prejudicar sua regularização" (FREIRE; OLIVEIRA, 2006, p. 120).

Em meio a este conflito de competências e interesses ocorreu o esbulho de grandes porções de terras tradicionalmente ocupadas por indígenas e que, por direito, eram suas. O relatório da Comissão Nacional da Verdade apresenta vários episódios que mostram como esta "fragilidade institucional" foi apropriada 
em processos de invasão e tomada de terras indígenas em todo o país promovidas tanto pelo governo federal quanto por governos estaduais.

No primeiro caso, podemos citar a chamada "Marcha para o Oeste" que, durante o governo de Getúlio Vargas, favoreceu a atração e contato com diversas populações indígenas nas regiões centro-oeste e norte na perspectiva de integrá-las ao projeto de expansão nacional e proteção das fronteiras. Este projeto provocou a morte de milhares de indígenas por motivos diversos invasão e tomada de territórios, doenças, conflitos etc. -, a desarticulação de modos de vida e o início de radicais processos de etnogênese.

No caso dos governos estaduais, a Comissão Nacional da Verdade destaca alguns casos exemplares:

Entre 1930 e 1960, o governo do estado do Paraná titula terras indígenas para empresas de colonização e particulares no oeste do estado. O governo de Moysés Lupion, em particular, notabiliza-se por práticas de espoliação de terras indígenas. Os interesses econômicos de proprietários se faziam representar nas instâncias de poder local para pressionar o avanço da fronteira agrícola sobre áreas indígenas. Em 1958, deputados da Assembleia Legislativa de Mato Grosso aprovaram o Projeto de Lei $n^{\circ} 1.077$, que tornava devolutas as terras dos índios Kadiweu. Em 1961, o Supremo Tribunal Federal decide pela inconstitucionalidade da lei, mas, a essa altura, estava estabelecida a invasão, uma vez que as terras já tinham sido loteadas. Além das invasões propriamente ditas, eram comuns arrendamentos de terras que não obedeciam às condições do contrato - quando este havia - ocupando enormes extensões de terras indígenas; constituindo, em alguns casos, situação de acomodação das irregularidades (invasões praticadas e posteriormente legalizadas pelo SPI por meio de contratos de arrendamento) (KEHL, 2014, p. 200).

Em outros tantos casos trazidos a público, os próprios agentes governamentais responsáveis pela proteção e tutela dos índios, primeiro no SPI e depois na FUNAI, são acusados de envolvimento em episódios de espoliação e facilitação de invasão de terras indígenas ocupadas:

Foram emitidas amiúde declarações oficiais fraudulentas que atestavam a inexistência de índios nas áreas cobiçadas por particulares. Para tomar posse dessas áreas e tornar real essa extinção de índios no papel, empresas e particulares moveram tentativas de extinção física de povos indígenas inteiros - o que configura um genocídio terceirizado - que chegaram a se valer de oferta de alimentos envenenados, contágios propositais, 
sequestros de crianças, assim como de massacres com armas de fogo (KEHL, 2014, p. 201).

Denúncias de corrupção, fraude e outras práticas contrárias aos interesses dos índios foram constantes durante os anos de atuação do SPI e da FUNAI. Aliás, estas práticas estão inclusive na origem da extinção do primeiro órgão indigenista governamental. O famoso, mas pouco estudado, "Relatório Figueiredo" de 1967 - que veio a público recentemente com suas mais de 7.000 páginas - está recheado de denúncias de corrupção e fraudes engendradas por funcionários públicos, tutores dos povos indígenas, em associação com indivíduos, governos e empresas. A CNV apresentou no seu texto um destes depoimentos constantes no relatório Figueiredo revelador dos problemas enfrentados pelos povos indígenas na garantira de seus direitos. Trata-se do depoimento de Helio Jorge Bucker, chefe de uma Inspetoria Regional do SPI:

[...] dos esbulhos de terras indígenas de que tenho conhecimento [...], nenhum foi mais estranho e chocante do que o procedido diretamente pelo Ministério da Agricultura, através do seu Departamento de Terras e Colonização. [...] O próprio órgão responsável pela garantia da terra do índio, é o primeiro a despojá-lo. Penso que fica bem claro com esse exemplo que a espoliação tem a chancela oficial das cúpulas administrativas, maiores responsáveis pelas desditas dos índios e do Serviço de Proteção aos Índios, o bufão da grande comédia (KEHL, 2014, p. 202).

Em muitos aspectos a nova agência indigenista do estado, a FUNAI, criada em 1967, manteve as práticas adotadas pelo SPI no processo de esbulho de territórios indígenas, sobretudo, se pensarmos que sua atuação ainda estava pautada pela premissa legal que definia a integração gradativa do índio à comunhão nacional. Muitos projetos capitaneados pela FUNAI, subordinados ao Ministério do Interior, tiveram por objetivo tornar populações indígenas em camponeses integrados ao sistema produtivo nacional o que provocou mudanças e processos de fixação em territórios que posteriormente serviram para reduzir os territórios tradicionais indígenas e atender determinados interesses agropecuários nas diversas regiões do país.

As consequências destas políticas e projetos engendrados por agentes do Estado a respeito das populações indígenas ainda se fazem sentir nos dias atuais. Um dos casos que recebeu destaque na imprensa nacional recentemente 
refere-se à etnia Xavante, mais especificamente ao processo de sedentarização deste povo decorrente dos contatos estabelecidos no contexto da "Marcha para o oeste" durante o governo de Getúlio Vargas. O incentivo governamental para a colonização da região central do território brasileiro levou colonos e fazendeiros para a região, conforme relato de antropólogos:

\begin{abstract}
À medida que os grupos xavantes cediam às pressões da expansão nacional, os territórios que Ihes haviam por mais de cem anos garantido a reprodução de seu modo de vida tradicional, tornavam-se acessíveis à colonização e, especialmente, à produção capitalista. Nos anos 1960 e 70, por incentivos fiscais do governo, destinados a fomentar a colonização e o desenvolvimento econômico em larga escala da região, colonos e fazendeiros chegaram por lá. O acesso a porções do território tradicional do povo Xavante envolveu, muitas vezes, fraudes. Sabe-se de casos em que, para disponibilizar terras à produção capitalista, autoridades alteraram mapas e atestaram a ausência de habitantes indígenas (GRAHAM, 2000, p. 106).
\end{abstract}

Os efeitos desastrosos das práticas governamentais não se fizeram sentir apenas nos episódios de corrupção para esbulho de territórios. No caso específico do povo Xavante, durante as décadas de 1970 e 80, a FUNAI começou a implantar projetos de cultivo mecanizado de arroz nas aldeias, visando a transformação dos indígenas em pequenos agricultores integrados à produção capitalista, isto é, visava suprir a carência de alimentos - causada sobretudo pela diminuição dos seus territórios tradicionais - e incentivar a produção de excedentes para comercialização. ${ }^{5} \mathrm{O}$ projeto foi abandonado, mas o hábito de comer arroz já havia se consolidado na população, assim como a perda de sementes oriundas da tradição alimentar Xavante; a partir da década de 1990 o consumo de alimentos industrializados se acentuou com a ampliação de políticas assistencialistas e com o aumento da circulação de dinheiro nas aldeias, de modo que, atualmente, o povo Xavante sofre com altos índices de diabetes dentre seus membros - as estimativas de pesquisadores e agentes de saúde mais recentes apontam para a índices próximos a $30 \%$ da população adulta (REIS, 2015).

Podemos visualizar, desta forma, que a atuação dos agentes governamentais em muitos casos concorre tanto para promover o esbulho de territórios indígenas quanto para desestruturar seus modos e saberes

${ }^{5}$ Sobre este processo consultar: Martins (2016). 
tradicionais, gerando problemas que se encontram no horizonte de desafios e expectativas destas populações nos dias atuais.

\section{Protagonismo indígena e resistência}

É figura comum no imaginário brasileiro a imagem do índio como um sujeito passivo, inocente, que foi atacado e destruído por uma lógica mercantil capitalista e externa a ele. Mesmo que os livros didáticos, de modo geral, tenham sido bem-sucedidos na desconstrução deste estereótipo, eles ainda engatinham diante da complexidade da discussão referente ao protagonismo histórico dos povos indígenas. Ainda é um desafio o debate e o entendimento dos indígenas como sujeitos ativos da história do contato, que efetivaram estratégias e políticas que atendiam a uma lógica própria ao grupo que pertenciam.

Se a historiografia referente aos povos indígenas brasileiros já incorporou amplamente $\mathrm{o}$ entendimento das diversas estratégias de resistência e sobrevivência dos índios diante das ameaças representadas pelos invasores de seus territórios - para o que contribuiu bastante os trabalhos de John Monteiro (2001) sobre o período colonial6 - o mesmo não pode ser dito sobre os livros didáticos de história do ensino fundamental. E neste sentido, o estudo da história indígena e do indigenismo durante o período republicano é, mais uma vez, fundamental, pois neste período os diversos povos indígenas incorporaram novas estratégias de luta e resistência diante dos diversos processos históricos vivenciados por eles.

As formas assumidas pelo protagonismo indígena na perspectiva de resistência diante dos processos decorrentes dos contatos com as frentes de expansão nacional durante o período republicano foram e ainda são diversas. 0 caso do esbulho das terras dos índios Kadiweu oficializado no final da década de 1950, mencionado anteriormente no relatório da Comissão Nacional da Verdade, pode ser usado como um exemplo interessante. Os Kadiweu obtiveram o reconhecimento de posse do território que até hoje habitam pelo imperador $D$.

\footnotetext{
6 Sobre as diversas formas de resistência indígena à invasão de seus territórios no período colonial consultar: Monteiro (1994, 2001).
} 
Pedro II em decorrência da participação de seus guerreiros na Guerra do Paraguai, no entanto, esta posse só foi oficialmente reconhecida em decreto expedido em 1903, já durante o período republicano. Mesmo com a demora do processo de demarcação e reconhecimento, os Kadiweu mantiveram-se resilientes por meio da memória coletiva, que celebra com orgulho a sua participação no conflito e a consequente posse do território. Mesmo com a demarcação oficial, os territórios kadiweus na serra da Bodoquena/MS começaram a ser alvo sistemático de invasões por posseiros no início da década de 1950, que se tornaram mais frequentes após o arrendamento de terrenos realizados com a autorização do SPI. Já nesta época os conflitos entre os indígenas e os fazendeiros eram frequentes. No início dos anos 1980, após a prorrogação do contrato de arrendamento das terras aos fazendeiros realizada pelo então presidente da FUNAI, Jurandir Fonseca Alves, os índios radicalizaram o conflito para reaver os mais de 300.000 hectares de terra mantendo como prisioneiros um fazendeiro e funcionários da FUNAI. A estratégia chamou a atenção da imprensa nacional e levou à destituição do presidente da FUNAI e a consequente nomeação de Gerson Alves para o cargo que, juntamente com o então deputado Mário Juruna, propôs um acordo para a devolução das terras ocupadas para os índios.

Este caso envolvendo as disputas pela posse do território dos Kadiwéu revela como as estratégias engendradas pelos indígenas para lidar com o assédio de seus territórios e recursos naturais são dinâmicas e gestados a partir de leituras e interpretações dos momentos históricos vivenciados por eles. É interessante observar como os Kadiweu souberam chamar a atenção dos veículos de comunicação não-indígenas bem como dos agentes governamentais e de políticos ligados a causa indígena para a solução do impasse em que se encontravam envolvidos.

Casos como este, que atestam o protagonismo das populações indígenas diante dos processos históricos vivenciados por eles, são facilmente encontrados na historiografia que trata do período republicano. Não obstante é importante destacar que este protagonismo foi historicamente redimensionado pelos indígenas a partir da incorporação e reelaboração sistemática de formas e estratégias políticas pertencentes à sociedade não-indígena, que se mostraram 
efetivas para a negociação de conquistas e direitos fundamentais à existência dos índios ao longo do tempo.

Na década de 1950, o contato de povos indígenas com sertanistas como os irmãos Orlando e Cláudio Villas-Bôas e Francisco Meirelles contribuiu para o aprofundamento da conscientização indígena a respeito dos mecanismos políticos de disputa e representação nacionais. Nas décadas seguintes, os indígenas radicalizaram as lutas pelo reconhecimento por parte do Estado e da sociedade brasileira de seus direitos de posse de seus territórios originários e de suas práticas culturais. Formando alianças com órgãos e entidades não-indígenas, como o Conselho Indígena Missionário (CIMI), a Associação Brasileira de Antropologia (ABA), o Museu do Índio, ONGs favoráveis à causa indígena que surgiam nos diversos estados, e vários outros, os índios passaram a se organizar em órgãos próprios ao sistema republicano, como sindicatos, associações e organizações para garantir e defender seus direitos, chegando mesmo a criar a União das Nações Indígenas (UNI), órgão de representação nacional que não chegou a ter o alcance que propunha. As associações locais e regionais foram fundamentais para o estabelecimento de uma "agenda indígena" para o país, uma vez que promoveram congressos, seminários e debates por todo o país, que se mostraram importantes para o fortalecimento de reivindicações históricas destes povos que foram incorporadas na elaboração da Constituição de 1988 - a votação do capítulo constitucional intitulado "Dos Índios" foi, inclusive, acompanhada no Congresso Nacional por representantes de várias etnias do país.

Após as conquistas decorrentes da Constituição de 1988 , o foco da luta dos povos indígenas foi deslocado. É claro que muitos deles ainda se veem às voltas com conflitos ocasionados pela invasão de seus territórios - o caso da reserva Raposa Serra do Sol é emblemático, bem como a situação dos indígenas Guarani-Kaiowá no Mato Grosso do Sul - mas, nas últimas décadas os povos indígenas se inseriram em outros espaços de lutas e reivindicações, como nos processos relativos ao uso e à conservação dos recursos naturais - mais recentemente o processo de definição e licitação da construção da usina hidrelétrica de Belo Monte/PA, no rio Xingu, revelou diferentes interpretações e estratégias desencadeadas pelas diversas etnias indígenas habitantes da região - 
, e também passaram a se inserir na política de forma institucionalizada através de candidaturas a cargos legislativos e do exercício do voto. Aos poucos, as diversas organizações indígenas passaram a construir acordos e aproximações com outros órgãos governamentais, além da FUNAI, como a FUNASA (saúde) e o MEC (educação), além de programas efetivados junto a outros ministérios, como o do Meio Ambiente, Desenvolvimento Agrário e Social etc. (FREIRE; OLIVEIRA, 2006, p. 197).

Todas estas formas de resistência e agendas de reivindicações estabelecidas pelos diversos povos indígenas brasileiros no período republicano demonstram, de uma vez por todas, que os indígenas não são sujeitos passivos de sua própria história, ao contrário, demonstram uma determinada concepção de historicidade, ou seja, revelam o quanto são cientes dos processos em que estão envolvidos e sujeitos das transformações que engendram. Somente a constatação deste protagonismo, no entanto, é insuficiente para enfrentarmos os desafios da história indígena nas escolas brasileiras. Este protagonismo, como demonstramos, é historicamente construído pelos indígenas diante de determinados processos históricos que precisam ser explorados, criticados e dimensionados para uma melhor compreensão das questões colocadas para estas populações no tempo presente.

A omissão de temas fundamentais para a compreensão dos desafios enfrentados pelos povos indígenas na contemporaneidade pelos livros didáticos de história do ensino fundamental cria lacunas que tornam ainda mais difícil a compreensão da realidade vivida por estes povos pelos estudantes. Por isso, acreditamos que os envolvidos com o ensino de história devem se debruçar seriamente sobre estes e outros temas - consideramos particularmente importante a abordagem do tema das migrações que as populações indígenas têm feito da aldeia para a cidade, por exemplo - para encontrar propostas didáticas adequadas para o devido dimensionamento da historicidade vivenciada pelos indígenas brasileiros.

\section{Referências}


BITTENCOURT, Circe F. (Org). O saber histórico na sala de aula. São Paulo: Ed. Contexto, 1997.

BOULOS JUNIOR, Alfredo. História: sociedade \& cidadania - edição reformulada. 2. ed. São Paulo: FTD, 2012.

BRAICK, Patrícia Ramos. Estudar História: das origens do homem à era digital. São Paulo: Moderna, 2011.

BRASIL. Lei 11.645, de 10 de março de 2008. Altera a Lei no 9.394, de 20 de dezembro de 1996, modificada pela Lei no 10.639, de 9 de janeiro de 2003, que estabelece as diretrizes e bases da educação nacional, para incluir no currículo oficial da rede de ensino a obrigatoriedade da temática "História e Cultura AfroBrasileira e Indígena". Disponível em: <http://www.planalto.gov.br/ccivil_03/ _Ato2007-2010/2008/Lei/L11645.htm>. Acesso em: 10 set. 2016.

CAMPOS, Flávio de; CLARO, Regina; DOLHNIKOFF, Miriam. História nos dias de hoje. São Paulo: Leya, 2012.

DOMINGUES, Joelza Ester. História em documento: imagem e texto. São Paulo: FTD, 2009.

FREIRE, Carlos Augusto da Costa; OLIVEIRA, João Pacheco de. A Presença Indígena na Formação do Brasil. Brasília: MEC, 2006.

GRAHAM, Laura. Os Xavante na cena pública. In: RICARDO, C.A. (Org.). Povos indígenas no Brasil, 1996-2000. São Paulo, Instituto Socioambiental, 2000.

GRUPIONI, Luís Donizete Benzi. Livros didáticos e fontes de informações sobre as sociedades indígenas no Brasil. In: GRUPIONI, Luís Donizete Benzi; SILVA, Aracy Lopes da (Org.). A Temática Indígena na Escola: novos subsídios para professores de $1^{\circ}$ e $2^{\circ}$ graus. Brasília: MEC/MARI/UNESCO, 1995.

KEHL, Maria Rita Relatório da. Violações de direitos humanos dos povos indígenas. In: COMISSÃO NACIONAL DA VERDADE. Relatório da CNV: Textos Temáticos. Brasília, 2014, v. 2, texto 5, p. 198-256.

MARINO, Denise Mattos; STAMPACCHIO, Léo. História. 4. ed. São Paulo: IBEP, 2012.

MARTINS, Ezequiel de Araújo. Análise acerca das transformações no modo de vida Xavante: um olhar sobre o manejo do solo na aldeia Namunkurá. 2016. Monografia (Especialização em História e Culturas dos Povos Indígenas) Universidade Federal de Uberlândia, 2016.

MONTEIRO, John Manuel. Negros da Terra: índios e bandeirantes nas origens de São Paulo. São Paulo: Companhia das Letras, 1994.

MONTEIRO, John Manuel. Tupis, Tapuias e Historiadores: estudos de história indígena e do indigenismo. 2001.Tese (Livre Docência) - Unicamp, Campinas, 2001. 
PANAZZO, Silvia; VAZ, Maria Luísa. Jornadas. hist. 2. ed. São Paulo: Saraiva, 2012.

REIS, Lucas. Refrigerante e doce provocam epidemia de diabetes em índios em MT. Folha de São Paulo, São Paulo, 9 ago. 2015. Cotidiano. p. 14.

Recebido em 23 de agosto de 2017 Aprovado em 28 de dezembro de 2017 